\title{
Influence of heat treatment on the microstructure and tensile properties of Ni-base superalloy Haynes 282
}

\author{
Ceena Joseph ${ }^{1}$, Christer Persson ${ }^{1}$, Magnus Hörnqvist Colliander ${ }^{2, a}$ \\ ${ }^{1}$ Chalmers University of Technology, Department of Materials and Manufacturing \\ Technology, S-41296 Göteborg, Sweden \\ ${ }^{2}$ Chalmers University of Technology, Department of Physics, S-41296 Göteborg, Sweden \\ acCorresponding author: magnus.colliander@chalmers.se, +46 317723306
}

\begin{abstract}
The effect of heat treatment on the microstructure and mechanical properties of Ni-base superalloy Haynes 282 was investigated. Applying a standard two-step ageing $\left(1010{ }^{\circ} \mathrm{C} / 2 \mathrm{~h}+\right.$ $788^{\circ} \mathrm{C} / 8 \mathrm{~h}$ ) to the as-received, mill-annealed, material resulted in a the presence of discrete grain boundary carbides and finely dispersed intragranular $\gamma^{\prime}$, with an average size of $43 \mathrm{~nm}$. This condition showed excellent room temperature strength and ductility. The introduction of an additional solution treatment at $1120{ }^{\circ} \mathrm{C}$ resulted in grain growth, interconnected grain boundary carbides and coarse $(100 \mathrm{~nm})$ intragranular $\gamma^{\prime}$. The coarser $\gamma^{\prime}$ led to a significant reduction in the strength level, and the interconnected carbides resulted in quasi-brittle fracture with a $50 \%$ reduction in ductility. Reducing the temperature of the stabilization step to $996{ }^{\circ} \mathrm{C}$ during ageing of the mill-annealed material produced a bi-modal $\gamma^{\prime}$ distribution, and grain boundaries decorated by discrete carbides accompanied by $\gamma^{\prime}$. This condition showed very similar strength and ductility levels as the standard ageing of mill-annealed material. This is promising since both grain boundary $\gamma^{\prime}$ and a bi-modal intragranular $\gamma^{\prime}$ distribution can be used to tailor the mechanical properties to suit specific applications. The yield strength of all three conditions could be accurately predicted by a unified precipitation strengthening model.
\end{abstract}

Keywords: Superalloy, heat treatment, carbides, gamma prime, ductility, strength 


\section{INTRODUCTION}

Nickel based superalloys are used for high temperature applications, such as gas turbines in aerospace and power generating industry, because of their good mechanical properties like high temperature strength, creep resistance and fatigue life, and corrosion resistance [1]. These alloys derive their strength primarily from precipitation of $\gamma^{\prime}$ phase within grains and additionally by carbide precipitation at grain boundaries [1-4]. The size, distribution, morphology and composition of microstructural features like $\gamma^{\prime}$ and carbides are essential to obtain the desired properties. Extensive research on nickel alloys suggests that the discrete morphology of carbides at grain boundaries is important for creep properties, grain size control, strength and ductility [5-7], while the $\gamma^{\prime}$ precipitate size, morphology and distribution primarily affect the strength of the alloy $[1,8]$. Consequently, the influence of heat treatment has always drawn attention as it controls microstructural constituents, distribution and morphology of constituent phases in nickel alloys [9-13].

Here we are concerned with the process-structure-property relationship in Haynes 282, which is a recently developed nickel base superalloy. Haynes 282 has excellent fabricability and good creep properties compared to competing alloys like Waspaloy [14]. The conventional heat treatment of this alloy is a two-step aging at $1010^{\circ} \mathrm{C} / 2 \mathrm{~h} / \mathrm{AC}$ and $788^{\circ} \mathrm{C} / 8 \mathrm{~h} / \mathrm{AC}$, which is carried out on mill-annealed material (solution annealed at temperatures between 1121 and $1149{ }^{\circ} \mathrm{C}$ ) [15]. The conventionally heat-treated alloy shows fine spherical $\gamma^{\prime}$ precipitates and discrete grain boundary carbide particles [14]. However, the effects of different heat treatments on the microstructure and mechanical properties of Haynes 282 are still under research, and e.g. Jackson and Reed [16] showed that it was possible to optimize both properties and productivity of another Ni-base superalloy, Udimet 720Li, by adapting the standard heat-treatment. Heattreatment processes are either two or three step processes; first the material is solutionized, followed by single or double step aging treatment. Solution heat treatment is done to dissolve the $\gamma^{\prime}$ and secondary carbide phases; and aging for the optimum precipitation of grain boundary carbides (sometimes referred to as stabilization treatment) and strengthening $\gamma$ phase upon cooling or after aging. The primary objective of this study was to determine how different aspects of the heat treatment influences morphology of microstructural features and its subsequent impact on room temperature tensile properties in Haynes 282. 


\section{EXPERIMENTAL}

\subsection{Material and heat treatment Procedure}

The material used in this study was Haynes 282 sheet of $3 \mathrm{~mm}$ thickness manufactured as per specification AMS5951. The delivery condition of the sheet was rolled and mill annealed (solution annealed in the range $1121-1177^{\circ} \mathrm{C}$ for unknown time followed by air cooling). The chemical composition of the alloy is given in Table 1. The average grain size of the material was ASTM 3.5. Samples of $2 \mathrm{~cm}^{2}$ were prepared for the heat treatment schedules as shown in Table 2. After solution treatment, the samples were cooled by water quenching (WQ) and after aging they were furnace cooled (FC). At each step of heat treatment schedule, samples were also water quenched and examined to understand the microstructural development.

Table1. Chemical composition of Haynes 282 in weight $\%$.

\begin{tabular}{|l|l|l|l|l|l|l|l|l|l|l|l|}
\hline Ni & $\mathbf{C r}$ & $\mathbf{C o}$ & $\mathbf{M o}$ & $\mathbf{T i}$ & $\mathbf{A l}$ & $\mathbf{F e}$ & $\mathbf{C}$ & $\mathbf{B}$ & $\mathbf{P}$ & $\mathbf{S}$ & $\mathbf{S i}$ \\
\hline Bal & 19.52 & 10.33 & 8.56 & 2.13 & 1.52 & 0.66 & 0.060 & 0.005 & 0.002 & $<0.002$ & 0.06 \\
\hline
\end{tabular}

Table 2. Heat treatment schedules.

\begin{tabular}{|c|c|c|c|}
\hline Referred as & Solution treatment & Aging step 1 & Aging step 2 \\
\hline $\begin{array}{c}\text { Solution treatment }+ \\
\text { aging (ST+A) }\end{array}$ & $1120 \mathrm{C} / 2 \mathrm{hr}(\mathrm{WQ})$ & $1010 \mathrm{C} / 2 \mathrm{hr}(\mathrm{FC})$ & $788 \mathrm{C} / 8 \mathrm{hr}(\mathrm{FC})$ \\
\hline $\begin{array}{c}\text { Mill annealed + } \\
\text { aging (MA+A) }\end{array}$ & - & $1010 \mathrm{C} / 2 \mathrm{hr}(\mathrm{FC})$ & $788 \mathrm{C} / 8 \mathrm{hr}(\mathrm{FC})$ \\
\hline $\begin{array}{c}\text { Mill annealed + low } \\
\text { temperature aging } \\
\text { (MA+LTA) }\end{array}$ & - & $996 \mathrm{C} / 2 \mathrm{hr}(\mathrm{FC})$ & $788 \mathrm{C} / 8 \mathrm{hr}(\mathrm{FC})$ \\
\hline
\end{tabular}

\subsection{Experimental procedures}

For microstructural studies, the samples were ground and polished using alumina suspension. They were ultrasonically cleaned and subsequently electrolytically etched with oxalic acid etchant for grain boundary etching and $\gamma^{\prime}$ etchant to reveal the features. The conditions for electrolytic etching varied with heat treatment conditions. Both optical microscope and scanning electron microscope (SEM) was used to characterize the microstructure and morphology of $\gamma^{\prime}$ precipitates, and carbides at the grain boundaries. 
Samples for hardness testing were prepared and tested according to ASTM standard E92. The Vickers macro-hardness of samples was measured with $10 \mathrm{~kg}$ load and an average of 10 measurements is reported in this study.

Tensile specimens were prepared by water jet cutting and then subjected to the different heat treatments schedules as shown in Table 2. The tensile specimens had a $60 \mathrm{~mm}$ long gauge section with a $10.2 \times 3.0 \mathrm{~mm}$ cross-section. Tensile testing was performed in a MTS servo hydraulic machine with displacement control of $0.6 \mathrm{~mm} / \mathrm{s}$. The tests were performed to a strain of $10 \%$ where the extensometer was removed, and then continued to failure. The strain at failure was measured on the fractured samples, and the values reported are the average of two measurements for each heat treatment. The fracture surfaces of the failed specimens were examined by SEM to study the fracture characteristics.

In addition, image analysis was performed using ImageJ software [17] on SEM images to estimate the size and volume fraction of $\gamma^{\prime}$ (see section 3.4.2 for details). Thermodynamic simulations were performed using JMatPro v.8 [18] with the Ni-base superalloy database.

\section{RESULTS AND DISCUSSION}

\subsection{Microstructure}

\subsubsection{Mill-annealed (MA)}

The optical microstructure of as-received mill annealed (MA) sheet is shown in Figure 1(a). The microstructure consists of fine grains of the order of $\sim 100 \mu \mathrm{m}$ with MC carbides (rich in $\mathrm{Ti}$ and Mo) and carbonitrides distributed in the rolling direction both inter- and intragranularly. The SEM image in Figure 1(b) shows no $\gamma^{\prime}$ particles in the grain interior. The grain boundaries were generally free from carbides, although occasionally discontinuous grain boundary carbides were also observed. The occasional presence of grain boundary carbides indicates an incomplete solutionizing process, or re-precipitation of carbides during cooling. $\mathrm{Cr}$-rich $\mathrm{M}_{23} \mathrm{C}_{6}$ carbides have been shown to precipitate at grain boundaries in Ni-base superalloys during slow cooling after solution treatment $[19,20]$. Note that the types of grain boundary carbides present are not further addressed in this paper, but will be investigated in detail a separate publication. Furthermore, the misorientation of individual grain boundaries will greatly affect the tendency for carbide precipitation during cooling [21], which can explain why only some boundaries are decorated in the MA state. 


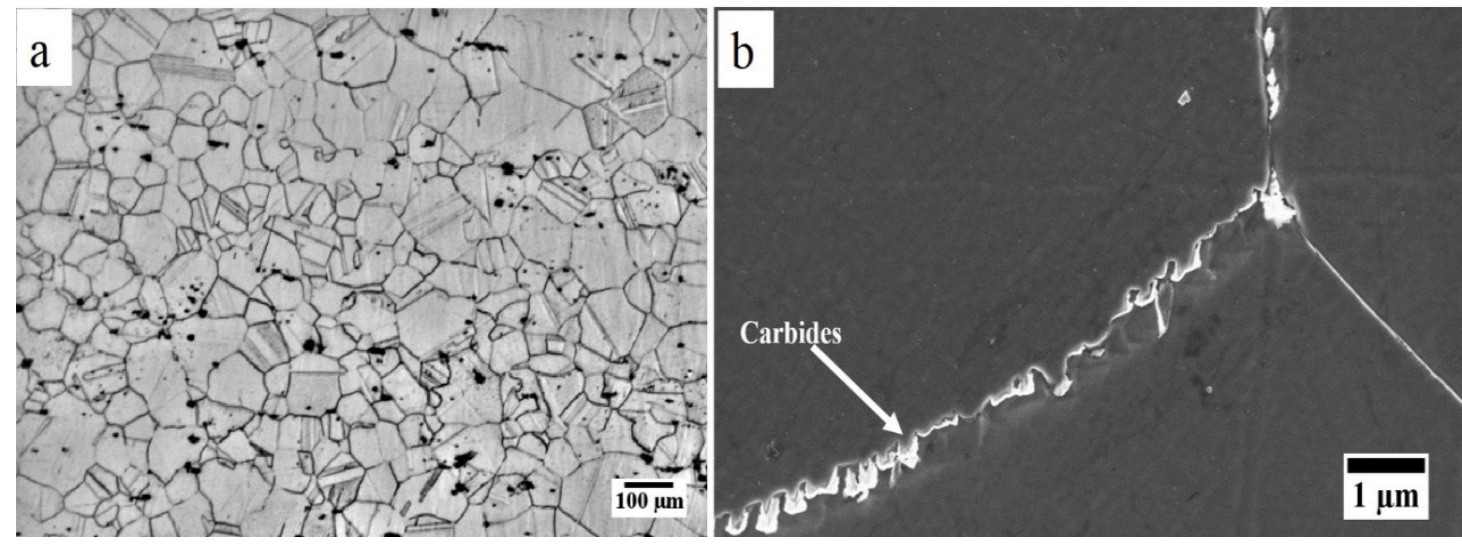

Figure 1. (a) As-received optical microstructure of Haynes 282 sheet; grain structure and presence of inter and intragranular MC carbides. (b) SEM of grain boundary carbides in asreceived condition. No traces of $\gamma^{j}$ can be seen in the grains.

\subsubsection{Solution treated + aged $(S T+A)$}

As can be seen in Figure 2(a), the microstructure of the alloy, after additional solutionizing and subsequent aging followed by furnace cooling, shows grain growth. The average grain size increases from $100 \mu \mathrm{m}$ to around $200 \mu \mathrm{m}$. The MC carbides and carbo nitrides are observed both inter- and intragranularly. After the solutionzing step at $1120{ }^{\circ} \mathrm{C}$ for $2 \mathrm{~h}$, the grain boundaries do not show presence of any form of carbides, rather just the intergranular MC carbides (Figure 3(a)). On subsequent aging at $1010{ }^{\circ} \mathrm{C}$ for $2 \mathrm{~h}$, the boundaries remain largely free of carbides, as shown in Figure 3(b), but occasional isolated carbide particles were noticed, which again may be related to the grain boundary misorientation [19]. After the second aging step, the carbides are fully developed into interconnected morphology (Figure 3(c)). The general absence of grain boundary carbides after the $1010{ }^{\circ} \mathrm{C}$ stage is surprising, as this is intended as a carbide stabilization treatment. One possible explanation relates to the observed grain growth during solutionizing. Assuming that there is an initial segregation of carbide formers to the grain boundaries from the processing, the migration of the boundaries during solutionizing will leave them in new positions, free of segregated elements. This will in turn affect the kinetics of precipitation due to the increased diffusion distance involved. If the carbide precipitation is sufficiently delayed, it will mainly take place during the subsequent 788 ${ }^{\circ} \mathrm{C}$ ageing step. Generally, low-temperature carbide precipitation in Ni-base superalloys have been reported to lead to different morphologies, typically detrimental to the alloy ductility [22, 23]. Interestingly, the grain boundaries after the full $\mathrm{ST}+\mathrm{A}$ treatment were much more difficult to etch compared to the MA state, or the MA+A (see next section), indicating that the grain boundary chemistry is different. It should be noted that the solutionizing time was relatively 
long in the present case, $2 \mathrm{~h}$, and that the use of shorter heat treatment times may avoid these issues.

No $\gamma^{\prime}$ can be observed until after the second aging step (Figure 4). When observed in higher magnification, the $\gamma$ 'precipitates primarily have cuboidal morphology after complete aging, as shown in Figure 4(c). Some precipitates also showed tendencies towards more irregular shapes. The size of the precipitates is in the order of $100 \mathrm{~nm}$.

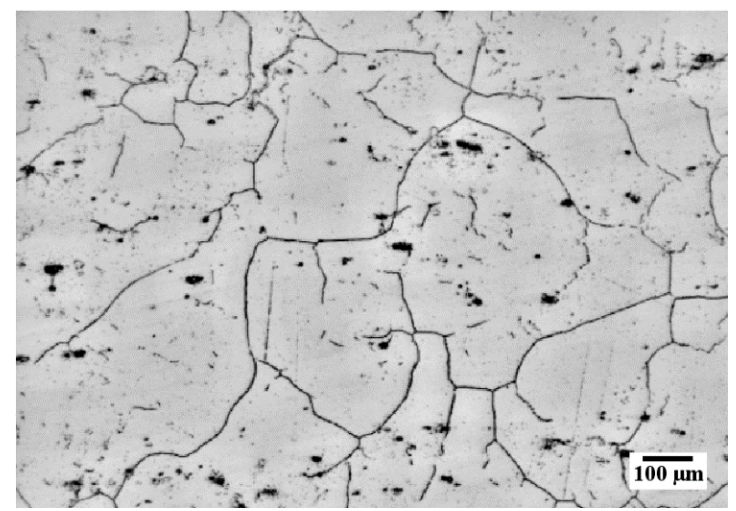

Figure 2. Optical microstructure of Haynes 282 sheet ST + A, showing grain growth.
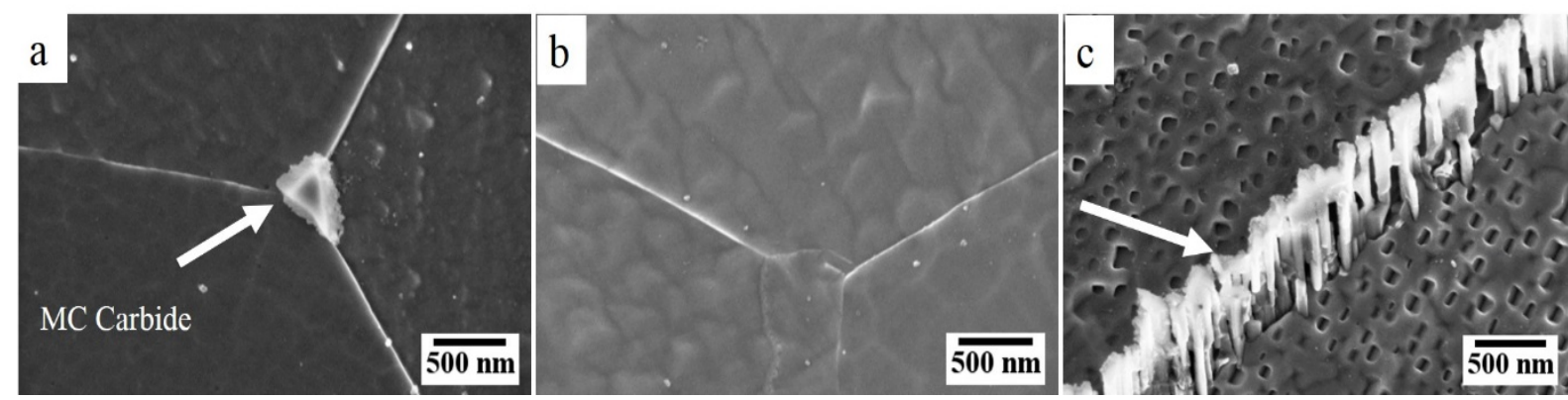

Figure 3. SEM showing formation of grain boundary carbides at each heat treatment stages (a) $1120^{\circ} \mathrm{C} / 2 \mathrm{~h} / \mathrm{WQ}$ (b) $1120^{\circ} \mathrm{C} / 2 \mathrm{~h} / \mathrm{WQ}+1010^{\circ} \mathrm{C} / 2 \mathrm{~h} / \mathrm{WQ}$ (c) Full heat treatment.
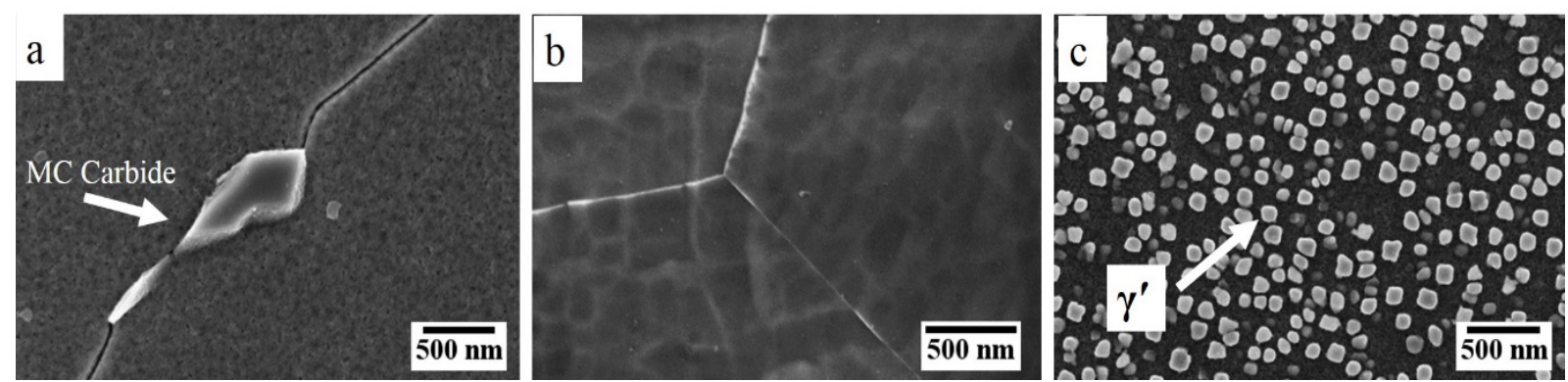

Figure 4. High resolution SEM image at each heat treatment stages (a) No $\gamma^{\prime}$ at $1120{ }^{\circ} \mathrm{C} / 2$ h/WQ (b) No $\gamma^{\prime} 1120^{\circ} \mathrm{C} / 2 \mathrm{~h} / \mathrm{WQ}+1010^{\circ} \mathrm{C} / 2 \mathrm{~h} / \mathrm{WQ}$ (c) Full heat treatment showing cuboidal $\gamma^{\prime}$ approximately $100 \mathrm{~nm}$ in size. 


\subsubsection{Mill-annealed + aged $(M A+A)$}

As can be seen in Figure 5, the microstructure after direct aging of the MA state followed by furnace cooling shows no grain growth. The average grain size is the same as in the as-received condition, $\sim 100 \mu \mathrm{m}$. The MC carbides and carbo nitrides are observed both inter- and intragranularly.

During the first step of aging at $1010^{\circ} \mathrm{C}$ for $2 \mathrm{~h}$ the grain boundaries show presence of discrete secondary carbides, as shown in Figure 6(a). On subsequent aging at $788^{\circ} \mathrm{C}$ for $8 \mathrm{~h}$, the carbides seem to still retain their discrete morphology, as shown in Figure 6(b). During the first aging step, $\gamma^{\prime}$ precipitation is observed (Figure 7(a)) while in the fully heat treated state, the $\gamma^{\prime}$ precipitates show spherical morphology with a size of the order of $50 \mathrm{~nm}$, see Figure 7(b). The presence of $\gamma^{\prime}$ after the $1010{ }^{\circ} \mathrm{C}$ step indicates that the solvus temperature might be slightly higher than reported previously for Haynes $282[14,24]$ and that obtained from JMatPro simulations $\left(1003{ }^{\circ} \mathrm{C}\right)$. The difference in $\gamma^{\prime}$ morphology between the $\mathrm{ST}+\mathrm{A}$ and $\mathrm{MA}+\mathrm{A}$ conditions is a result of the sphere-to-cube transition occurring with increasing particle size in order to minimize the misfit strain energy [21]. The reason for the finer $\gamma^{\prime}$ size in the MA+A condition, compared to the $\mathrm{ST}+\mathrm{A}$, is not clear at present, since they would be expected to respond very similarly to the ageing treatments. A potential explanation could be that the 1120 ${ }^{\circ} \mathrm{C}$ treatment for $2 \mathrm{~h}$ is sufficient to allow further recovery of the initial deformation structure from processing. If $\gamma^{\prime}$ preferentially nucleate at dislocations, the reduced density of dislocations after the recovery process would lead to fewer nucleation points and thus fewer, coarser precipitates. However, this remains to be investigated in future studies.

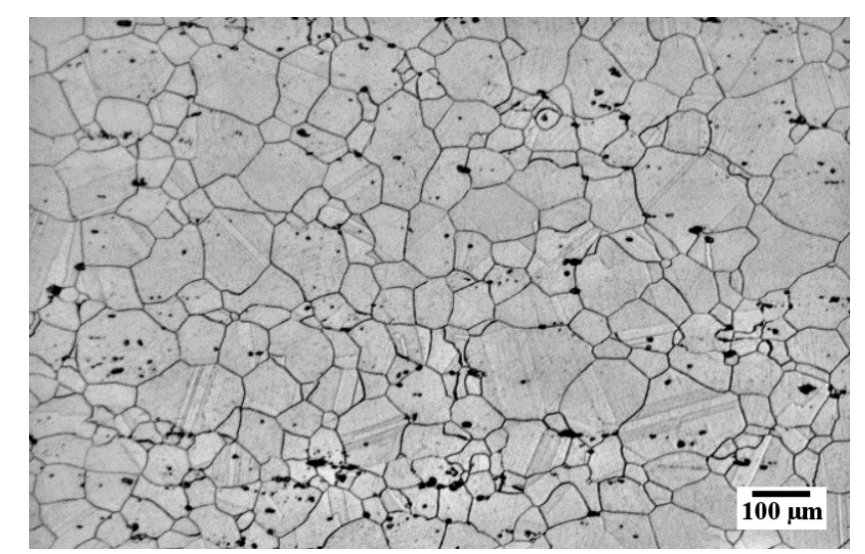

Figure 5. Optical microstructure of Haynes 282 sheet heat treated $M A+A$ showing grain size of $100 \mu \mathrm{m}$. 

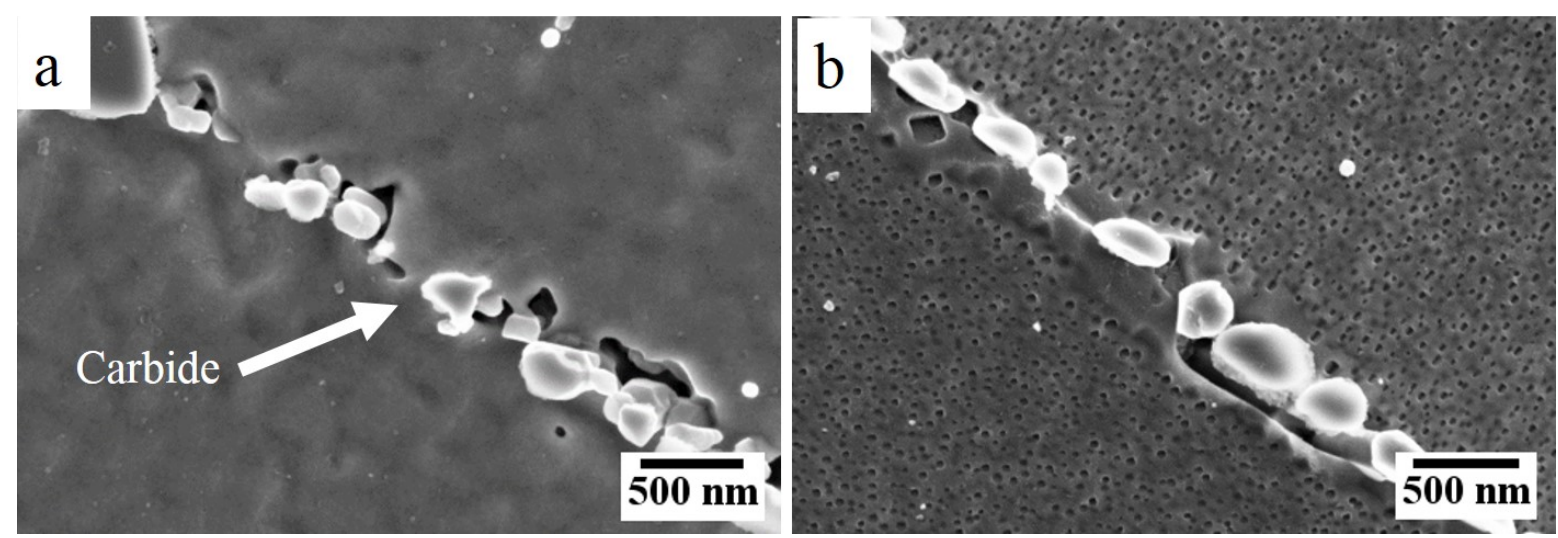

Figure 6. SEM image showing presence of discrete carbides at the grain boundary in (a) $\mathrm{MA}+1010^{\circ} \mathrm{C} / 2 \mathrm{~h}$ WQ (b) Fully heat treated state MA $+\mathrm{A}$.
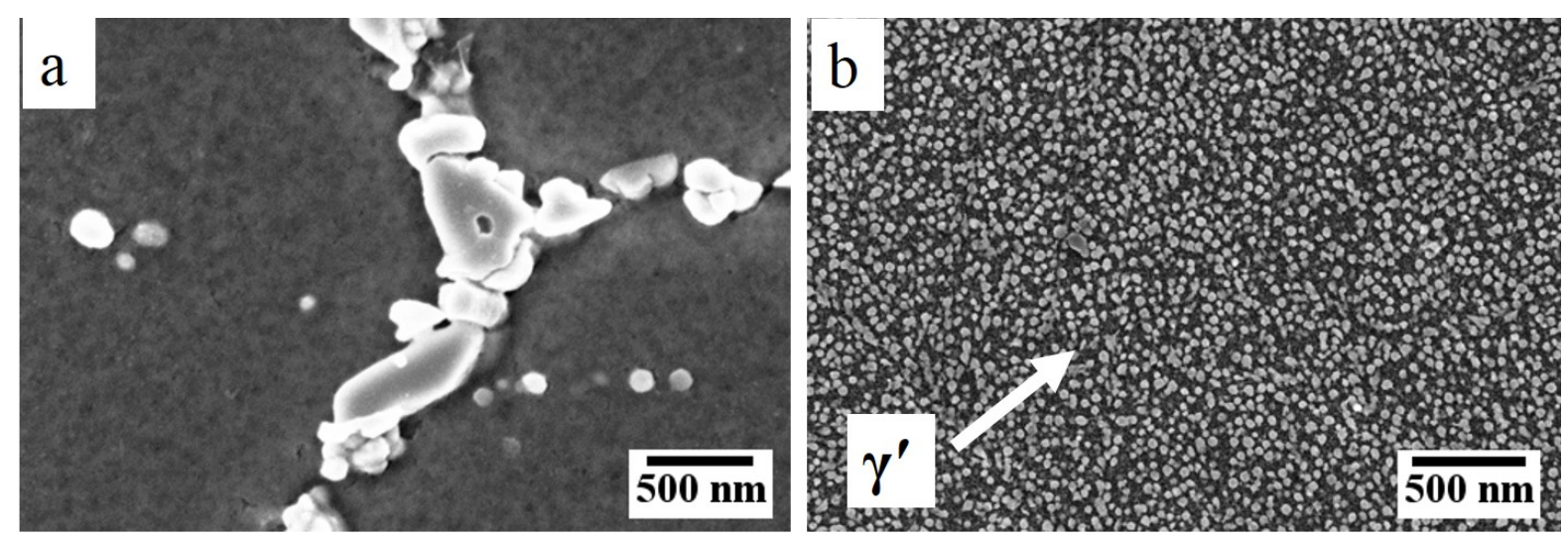

Figure 7. (a) Few $\gamma^{\prime}$ was observed $\mathrm{MA}+1010^{\circ} \mathrm{C} / 2 \mathrm{~h}$ WQ (b) After full heat treatment $\mathrm{MA}+\mathrm{A}$, spherical $\gamma$ with a size of $40-50 \mathrm{~nm}$ could be seen.

\subsubsection{Mill-annealed + low-temperature aged $(M A+L T A)$}

The microstructure of the alloy after low temperature aging followed by furnace cooling shows no grain growth (Figure 8). The average grain size was $\sim 100 \mu \mathrm{m}$, and MC carbides and carbo nitrides are observed both inter- and intragranularly. During the first step of aging at $996{ }^{\circ} \mathrm{C}$ for $2 \mathrm{~h}$, the grain boundaries show presence of secondary carbides along with $\gamma$ precipitates (Figure 9(a)). On subsequent aging at $788^{\circ} \mathrm{C}$ for $8 \mathrm{~h}$, the carbides remain as discrete particles in the boundaries, along with $\gamma$ p precipitates, which have now coarsened, as shown in Figure 9(b).

Figure 10 shows the presence and distribution of $\gamma^{\prime}$ precipitates at subsequent stages of heat treatment. As shown in Figure 10(a) after $996{ }^{\circ} \mathrm{C}$ for $2 \mathrm{~h}, \gamma^{\prime}$ precipitates are formed at grain boundaries and also sparsely within grains. On subsequent aging for $8 \mathrm{~h}$ at $788{ }^{\circ} \mathrm{C}$, these primary intragranular $\gamma^{\prime}$ precipitates grow and form the coarse $\gamma^{\prime}$ family (Figure 10(b)) with 
irregular morphology, around $175 \mathrm{~nm}$ in size. During the second aging step a secondary $\gamma^{\prime}$ family precipitates, smaller in size (around $40 \mathrm{~nm}$ ) and spherical morphology yielding a bimodal distribution. The occurrence of irregular shaped $\gamma^{\prime}$ has been shown to be related to the morphological instability, where the potential for "dendritic precipitation" is inherent during diffusion-controlled growth of spherical particles above a critical size into a super-saturated matrix [26]. The symmetric shape is usually conserved by other balancing contributions, but in the special situation where all the conditions outlined by Doherty [27] are fulfilled, irregular shapes or dendrites can develop. These conditions are: (i) isotropic interfacial energy; (ii) low diffusivity in the precipitate; (iii) low lattice mismatch; and (iv) widely spaced precipitates. Whereas superalloys usually fulfill the first three conditions, the last conditions typically not met. In the present case, however, the $\gamma^{\prime}$ particles precipitated at $996{ }^{\circ} \mathrm{C}$ are spaced widely enough to avoid soft impingement from overlapping diffusion fields. The formation of irregular shaped or dendritic $\gamma^{\prime}$ in Ni-base superalloys have been thoroughly investigated by Ricks et al. [28], showing deviation from spherical shape at particle sizes of 200-6700 nm, depending on the alloy. In comparison ,the critical size for morphological instability appears to be rather small in Haynes 282, as early stages of irregular shape development can be seen in the ST+A material (Fig. 4(c)).

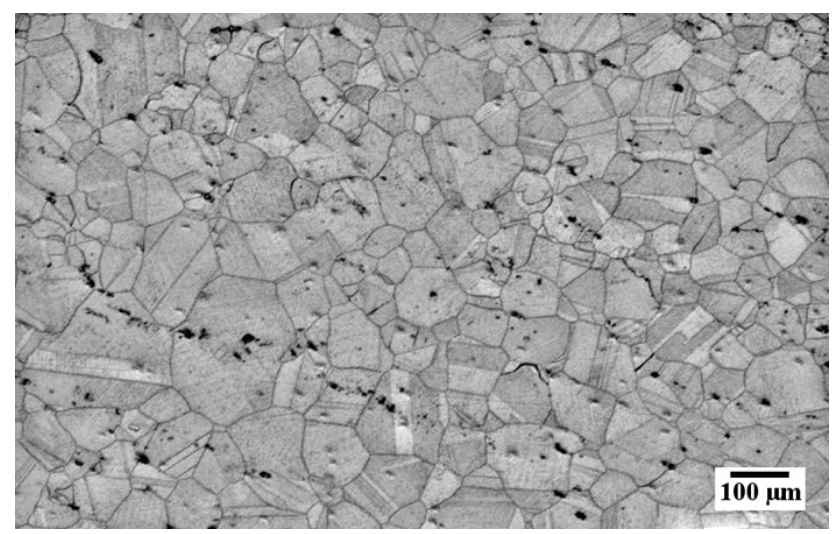

Figure 8. Optical microstructure of Haynes 282 sheet heat treated at MA+LTA, grain size of $100 \mu \mathrm{m}$. 

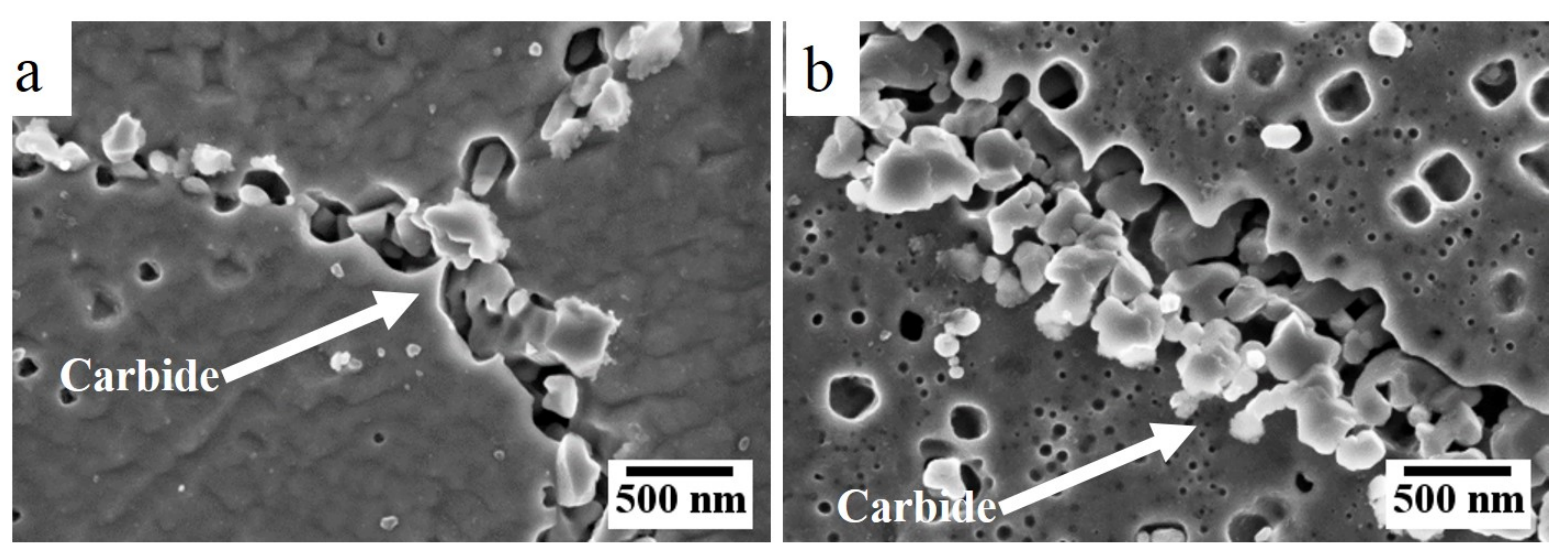

Figure 9. SEM image showing presence of discrete carbides in (a) MA $+996{ }^{\circ} \mathrm{C} / 2 \mathrm{~h}$ WQ (b)Fully heat treated state MA+LTA, contains discrete grain boundary carbides.
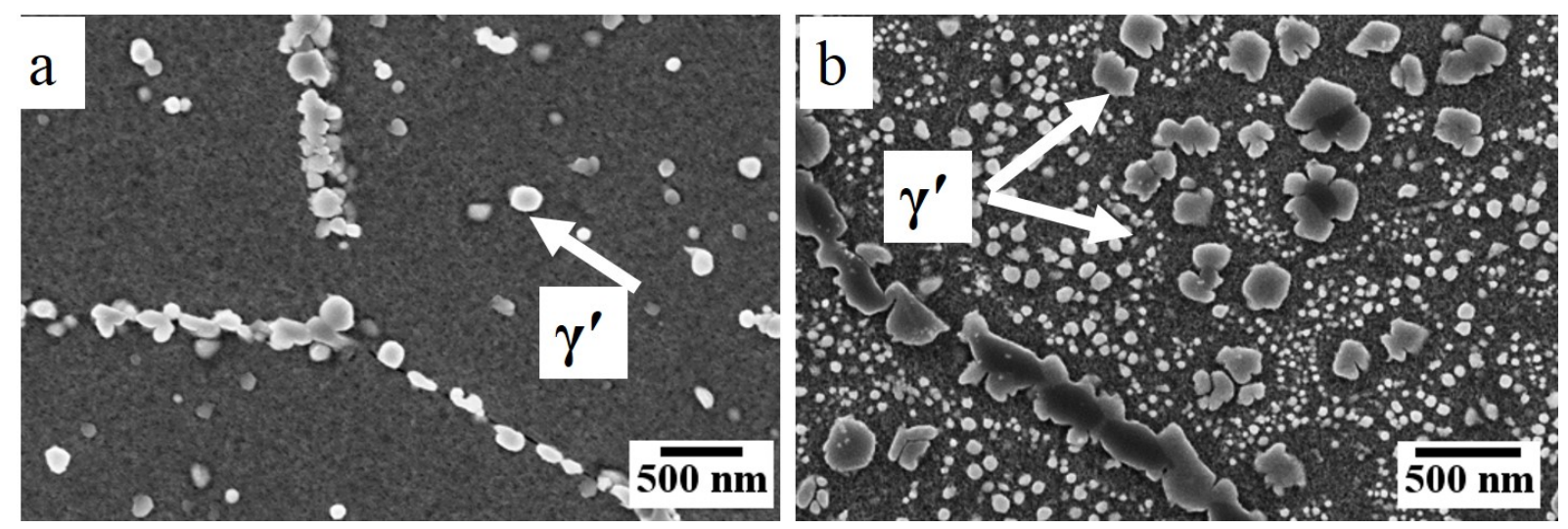

Figure 10. (a) $\gamma$ precipitation an the grain boundaries after MA $+996{ }^{\circ} \mathrm{C} / 2 \mathrm{~h} \mathrm{WQ}$. (b)Fully heat treated state, MA+LTA, showing large irregularly shaped $\gamma$, along with a secondary family of small spherical $\gamma$.

\subsection{Mechanical properties}

\subsubsection{Hardness}

Figure 11 shows the hardness during different stages of the heat treatments. The hardness of the as-received MA condition is shown as a dashed line. As can be seen, neither the $1010{ }^{\circ} \mathrm{C}$ nor the $996{ }^{\circ} \mathrm{C}$ ageing significantly affected the hardness, whereas the $1120{ }^{\circ} \mathrm{C}$ step resulted in a noticeable decrease (which was not altered by the subsequent $1010{ }^{\circ} \mathrm{C}$ treatment). The decrease in hardness after solution treatment can be rationalized in two ways: (i) the increase in grain size leading to a reduction in strength according to the Hall-Petch relationship; (ii) the cooling rate from the MA treatment, was not fast enough to prevent the precipitation of very small $\gamma^{\prime}$ precipitates, which are subsequently dissolved during the solution treatment stage. As the $\gamma^{\prime}$ solvus was shown to be higher than $1010^{\circ} \mathrm{C}$, although most likely not by much, the 
hardness would be expected to increase during the stabilization treatment of the MA condition at $1010{ }^{\circ} \mathrm{C}$ or $996{ }^{\circ} \mathrm{C}$ in the presence of small cooling-induced $\gamma^{\prime}$. It could also be argued that the small $\gamma^{\prime}$ could have a slightly lower solvus temperature, in which case they would dissolve at $1010{ }^{\circ} \mathrm{C}$ leading to softening of the MA material during stabilization at this temperature. None of these effects can be observed in Fig. 11. On the other hand, the decrease (around 30 $\mathrm{HV}$ ) is greater than typically observed for solution treated precipitation hardened superalloys, such as Waspaloy [31] and Alloy 718 [32], for a factor of two change in grain size. Thus, the reason for the decrease in hardness with solution treatment in not established in the present case.

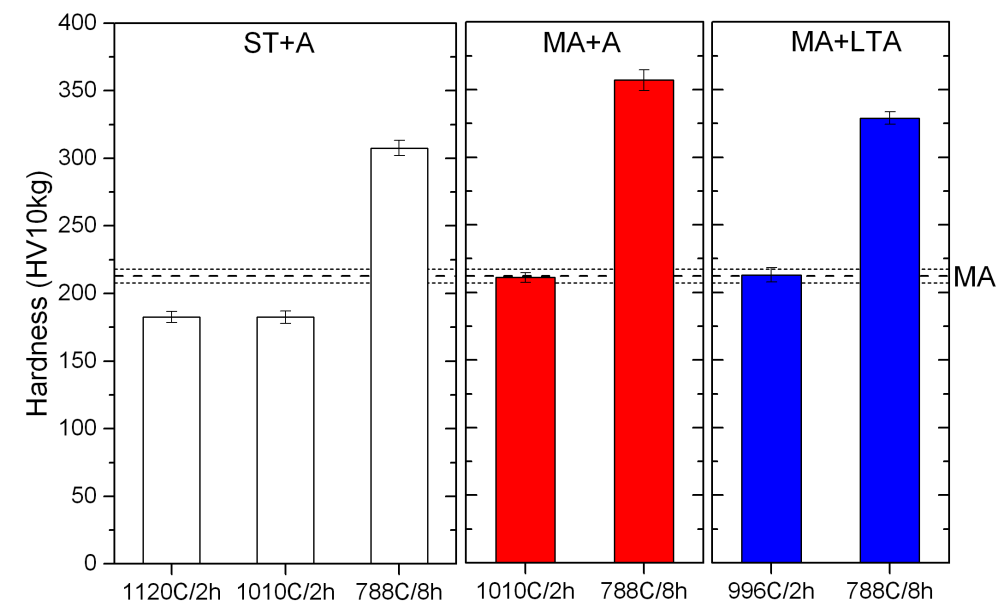

Figure 11. Development of the hardness after the different stages of heat treatment (error bar represents standard deviations). The dashed line marked MA is the hardness of the as-received (mill-annealed) material, with the standard deviation indicated by the dotted lines.

The fact that the $996{ }^{\circ} \mathrm{C}$ treatment does not result in a noticeable hardness increase, indicates that the volume fraction of intragranular $\gamma^{\prime}$ is small, in agreement with the SEM observations (Figure 10(a)). The equilibrium volume fraction at $996{ }^{\circ} \mathrm{C}$ is around 0.015 , according to JMatPro calculations (see Figure 12(a)), but as shown in Figure 10(a), a considerable fraction of this has precipitated in the grain boundaries and will not contribute to strengthening. The observed intragranular $\gamma^{\prime}$ are large and far between. This is also in agreement with predictions from JMatPro suggesting that the $\gamma^{\prime}$ formed during a $996{ }^{\circ} \mathrm{C} / 2 \mathrm{~h}$ treatment could reach a size of around $100 \mathrm{~nm}$, in fair agreement with the SEM observations. The interparticle spacing can be calculated as

$$
L=d\left(\frac{\pi}{6 f}\right)^{1 / 2}
$$


where $d$ is the particle diameter and $f$ is the voume fraction, which becomes around 500-700 $\mathrm{nm}$ for volume fractions of $0.01-0.02$ and particle size of $100 \mathrm{~nm}$. Again, this is consistent with the SEM observations.

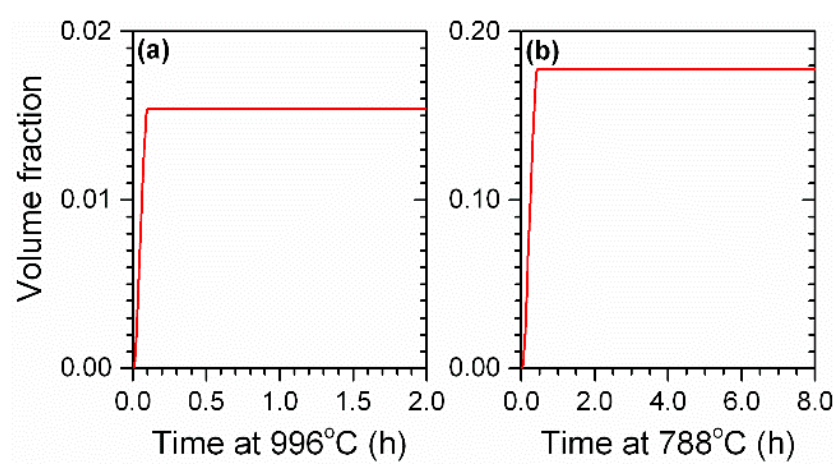

Figure 12. Development of the $\gamma^{\prime}$ volume fraction with time at (a) $996{ }^{\circ} \mathrm{C}$, and (b) $788^{\circ} \mathrm{C}$.

\subsubsection{Tensile properties}

Examples of stress-strain curves for the three conditions at room temperature can be seen in Figure 13(a), and the resulting tensile properties are given in Table 3. Also included in Table 3 is the macro-hardness of the as-received state and the three heat treated conditions for comparison. Clearly, the increase in $\gamma^{\prime}$ size in the ST+A condition markedly reduced the strength level. In addition, there is a $50 \%$ reduction in the ductility for the ST+A condition compared to MA+A and MA+LTA. Stability studies on carbides show that discrete morphologies are beneficial for the ductility as compared to cellular or platelet morphology [21]. This is consistent with that observed in ST+A condition where carbides are seen as interconnected. The presence of the interconnected carbide morphology is related to the fact that the introduction of the $1120{ }^{\circ} \mathrm{C} / 2 \mathrm{~h}$ solutionizing step results in the absence of carbide precipitation during subsequent ageing at $1010{ }^{\circ} \mathrm{C}$, as discussed previously. Instead, the carbides are precipitated at the second ageing step, at $788{ }^{\circ} \mathrm{C}$, leading to the unfavorable morphology. In the MA+LTA condition, the bimodal $\gamma^{\prime}$ distribution does not significantly affect the strength levels, and the maintained discrete carbide morphology preserves the ductility.

Figure 13(b) shows the strain hardening rate $(\theta=\mathrm{d} \sigma / \mathrm{d} \varepsilon)$ calculated from the true stress-strain curves for the different conditions. The strain hardening behavior is very similar in the MA+A and MA+LTA conditions, showing a plateau after the initial elastic-plastic transition (stage II) followed by a linear decrease with stress (stage III). This is consistent with other observations 
of Ni-base superalloys [31-33]. The stage II hardening rate, $\theta_{\mathrm{II}}$, is very close to the expected athermal hardening rate $\left(\theta_{\mathrm{II}}=M^{2} \mu / 200\right)$, and consistent with the rates observed for shearable precipitates $(d<80 \mathrm{~nm})$ in $\mathrm{X}-750$ [29]. The $\mathrm{ST}+\mathrm{A}$ condition shows a much lower level of $\theta_{\mathrm{II}}$, and fractures suddenly before stage III is reached. In contrast, Del Valle et al [31] observed a general increase in $\theta_{\text {II }}$ with increasing particle size. This discrepancy might be the much larger volume fraction in Haynes 282. In other systems with shearable precipitates, such as $\mathrm{Al}-\mathrm{Mg}-\mathrm{Si}$ and $\mathrm{Al}-\mathrm{Mg}-\mathrm{Zn}, \theta_{\mathrm{II}}$ decreased with increasing ageing time (particle size) in the under- to peakaged states [34]. The sudden fracture can be connected to the failure mode, which will be further treated later.

The onset of necking due to geometric instability (Considére's condition) occurs when the strain hardening rate is equal to the true stress $(\theta=\sigma)$. If the necking point calculated from Considére's condition (see Fig. 13(b)) is translated to engineering quantities, it corresponds well to the maximum stress in the engineering stress-strain curve for the MA+A and MA+LTA cases, as indicated by arrows in Fig. 13(a). For the ST + A treatment, on the other hand, the failure occurs long before Considére's condition is fulfilled.
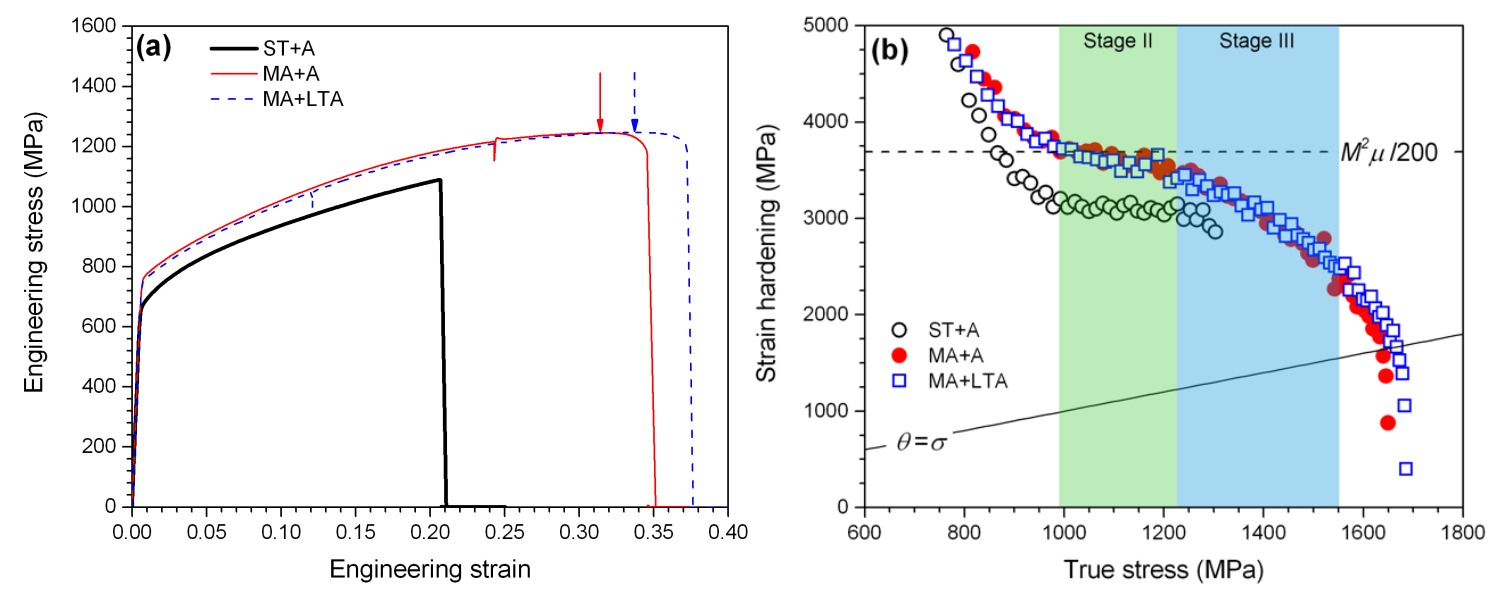

Figure 13. (a) Engineering tensile curves for the different conditions. (b) Strain hardening rate calculated from the true stress-strain curves, showing the presence of stage II and stage III hardening. The geometric condition for on-set of necking is defined by the intersection of $\theta$ and $\sigma$ in (b), and the corresponding points are marked by arrows in (a).

Of great interest is to note that the MA+LTA condition showed similar strength levels as the $\mathrm{MA}+\mathrm{A}$, and no loss of ductility. The lower temperature in the first ageing step resulted in the presence of $\gamma^{\prime}$ in the grain boundaries, in addition to discrete carbides particles. The grain 
boundary $\gamma^{\prime}$ could potentially play a large role in the high-temperature behavior, in particular the resistance to creep and grain boundary sliding. The lower ageing temperature also resulted in a bi-modal $\gamma^{\prime}$ distribution in the grain interiors, which could be used to optimize the resistance of the material to creep and fatigue loadings at high temperatures. Fine $\gamma^{\prime}$ has been shown to be beneficial for the creep resistance $[35,36]$ and dwell-crack growth resistance of superalloys [36]. The presence of coarse particles, on the other hand, can potentially provide an improved resistance to fatigue crack initiation, since Orowan looping acts to homogenize the slip and reduce stress concentrations in the microstructure [37]. Thus, the grain boundary $\gamma^{\prime}$ and bimodal intragranular distribution could offer a possibility to tune the mechanical properties of the alloy depending on application by controlling the time and temperature of the first ageing step.

Table 3. Mechanical properties for different heat treatment conditions

\begin{tabular}{|l|l|l|l|l|l|}
\hline & $\mathbf{0 . 2} \%$ YS & UTS & Elongation & Area reduction & Hardness \\
\hline Heat treatment & $\mathbf{( M P a )}$ & $\mathbf{( M P a )}$ & $\mathbf{( \% )}$ & $\mathbf{( \% )}$ & $\mathbf{( H V 1 0 k g )}$ \\
\hline As received (MA) & - & - & - & - & $212 \pm 4$ \\
\hline ST+A & $650 \pm 0$ & $1100 \pm 10$ & $16 \pm 1$ & $14 \pm 1$ & $310 \pm 6$ \\
\hline MA+A & $760 \pm 8$ & $1245 \pm 10$ & $32 \pm 1$ & $33 \pm 2$ & $358 \pm 8$ \\
\hline MA+LTA & $765 \pm 8$ & $1255 \pm 10$ & $32 \pm 1$ & $34 \pm 1$ & $327 \pm 6$ \\
\hline
\end{tabular}

\subsection{Fractography}

In order to understand the effect of heat treatment on the fracture behavior, the fracture surfaces were examined by SEM. As can been seen in Figure 14, the ST+A specimens showed mixed (intergranular+transgranular) ductile mode of failure. The carbides in the grain boundaries show distinct signs of cracking (as shown by arrow). For this condition the elongation was measured to be $16 \%$. In contrast, both MA+A and MA+LTA specimens showed intergranular failure resulting from ductile tearing of the boundaries, with a large amount of small dimples (Figures 15 and 16). For these conditions, there was no evidence for carbide cracking in the grain boundaries. The corresponding elongation was measured to be $32 \%$ in both cases. Clearly, the fracture behavior is distinctly affected by the grain boundary carbide morphology, where the interconnected structure in the ST+A condition shows reduction in the recorded elongation. Presumably, the interconnected structure of brittle carbides allows easy propagation of cracks initiated by the local fracture of carbides. This is not the case for discrete carbides, where the load is instead transferred to the ductile $\gamma$ matrix upon carbide fracture. The presence 
of grain boundary $\gamma^{\prime}$ in the MA+LTA material did not have a noticeable effect on the fracture mode, in agreement with the unaffected ductility compared to the MA+A case.
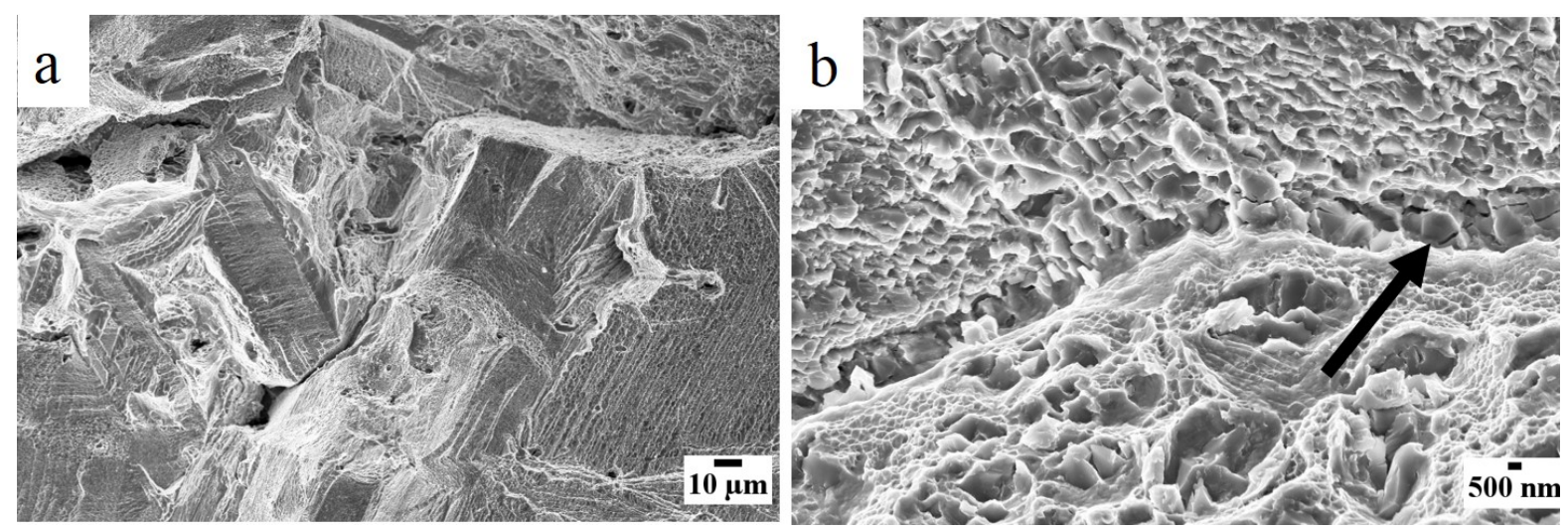

Figure 14. Fractographs of the $\mathrm{ST}+\mathrm{A}$ condition (a) Overall view showing mixed intergranular and transgranular failure. (b) Cracking of grain boundary carbides (arrow).
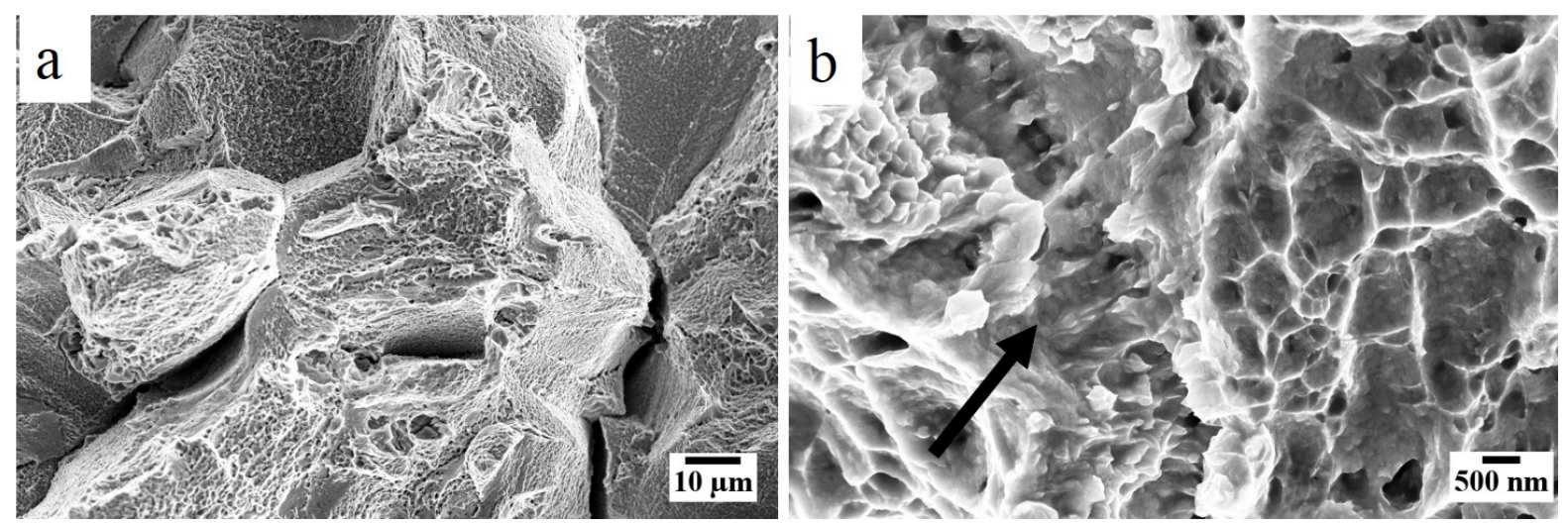

Figure 15. Fractographs of the $M A+A$ condition (a) Intergranular failure. (b) Ductile tearing of grain boundary and presence of fine dimples.
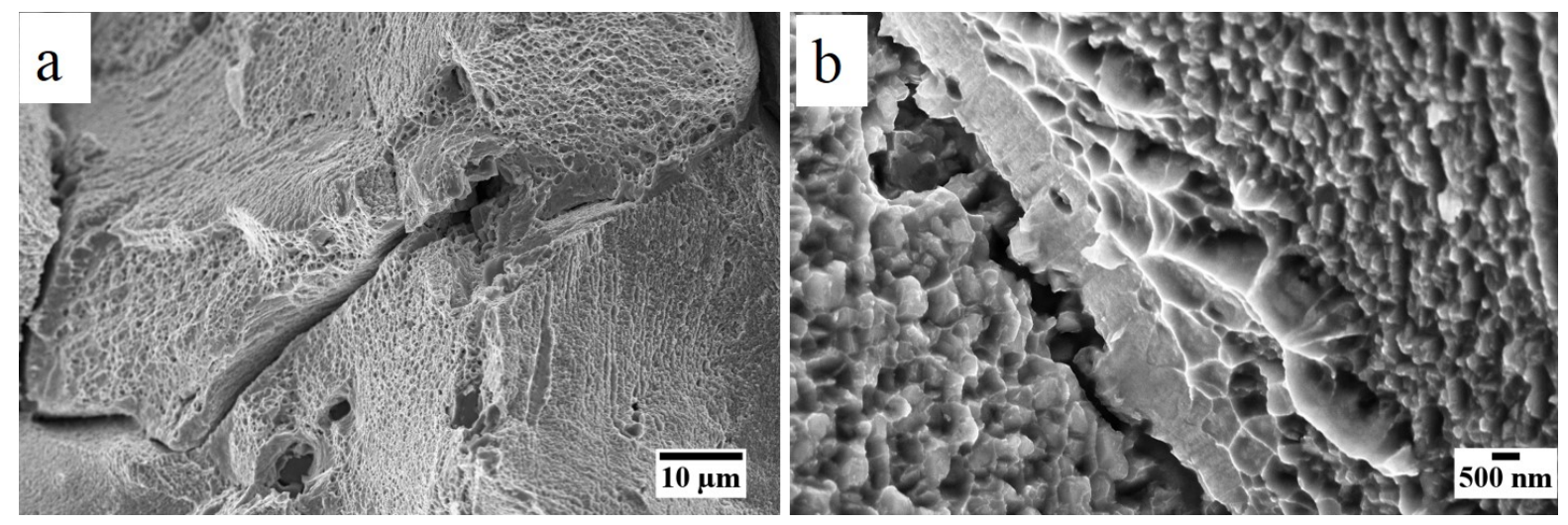

Figure 16. Fractographs of the MA+LTA condition (a) Intergranular failure (b) Ductile tearing of grain boundary and presence of fine dimples. 


\subsection{Yield strength prediction}

\subsubsection{Precipitation strengthening model}

It is of great interest to apply theoretical models in order to predict the mechanical properties resulting from a given microstructure. In particular, yield strength predictions received renewed attention in recent years, with a number of models for unimodal [38] and multimodal [39, 40] Ni-base superalloys being proposed. Here we attempt to predict the yield strength of Haynes 282 in the three different heat treatment conditions based on the model developed by GalindoNava et al. [40]. The reason for choosing this model is the simplicity of the unified approach taken, where the dominant mechanisms, shearing controlled by weak or strong pair-coupling, are reconciled into a single equation. The strength resulting from a population of precipitates of diameter, $d$, with a volume fraction, $f$, is given by:

$$
\sigma_{p}=\frac{M \gamma_{A P B}}{2 b} \frac{l}{\Lambda+d} \text {. }
$$

where $M$ is the Taylor orientation factor, $\gamma_{\mathrm{APB}}$ is the anti-phase boundary energy of the $\gamma^{\prime}$ phase, $l$ is average the segment length of the leading dislocation acting in the cutting of a particle, $b$ is the Burgers vector, $\Lambda$ is the average effective length of the leading dislocation driving particle cutting. The length of the leading dislocation cutting the precipitates is expressed as

$$
l= \begin{cases}d & \text { if } d<d_{m} \\ \left(d^{2}-\left(d-d_{m}\right)^{2}\right)^{1 / 2} & \text { if } d \geq d_{m}\end{cases}
$$

where

$$
d_{m}=\frac{\mu b^{2}}{\gamma_{A P B}}
$$

is the particle size corresponding to maximum strength (transition from weak to strong pair coupling). Here $\mu=82 \mathrm{GPa}$ [15] is the shear modulus. The effective length of the leading dislocation driving particle cutting is also determined by the cutting mechanism, and is given by

$$
\Lambda=\max \{\lambda, L-l\} .
$$

where $\lambda$ is the Friedel sampling length

$$
\lambda=\left(\frac{2 T}{d \gamma_{A P B}}\right)^{1 / 2}
$$

representing the mean distance between particles encountered by a bowing dislocation along it's length (weak pair coupling), $T=0.5 \mu b^{2}$ is the dislocation line tension, and $L$ according to Eq. (1) is the mean particle spacing.

In case of a multimodal distributions, the strength is given by 


$$
\sigma_{p}=\sum_{i} w_{i} \sigma_{i}=\frac{M \gamma_{A P B}}{2 b} \sum_{i}\left(\frac{w_{i} l_{i}}{\Lambda_{i}+d_{i}}\right)
$$

where the subscript $i$ denotes the $i^{\text {th }}$ family in the multimodal distribution and $w_{i}=N_{i} / N_{\text {tot }}$ is the number fractions of $\gamma^{\prime}\left(N_{i}\right.$ is the number of particles in the $i^{\text {th }}$ family and $N_{t o t}$ is the total number of particles, i.e. $\sum_{i} w_{i}=1$ ). The major unknown in the model above is the value of $\gamma_{A P B}$, which is not generally available for specific alloys. Several attempts have been made to experimentally determine $\gamma_{A P B}$ for $\mathrm{Ni}_{3} \mathrm{Al}$ [41-43], $\mathrm{Ni}_{3}(\mathrm{Al}, \mathrm{Hf})$ [44], Ni-Al-Sn [45], Ni-Al-V [45] and more generally $\gamma^{\prime}$ in Ni-Fe-base superalloys [46-48]. The reported values typically range from 0.15 to $0.3 \mathrm{~J} / \mathrm{m}^{2}$, but most results for Ni-Fe-base superalloys fall in the range $0.17-0.250 \mathrm{~J} / \mathrm{m}^{2}$. In the present case $\gamma_{A P B}$ can be considered as a fitting parameter, and is chosen to $0.18 \mathrm{~J} / \mathrm{m}^{2}$, which provides the best overall fit to the experimental data. Comparing the equilibrium $\mathrm{Ti} /(\mathrm{Ti}+\mathrm{Al})$ ratio of $\gamma^{\prime}$ in Haynes 282 from JMatPro simulations, a value in the lower end of the measured range is indeed expected based on the observations by Vittori et al. [46]. It is also consistent with results obtained for Ni-Fe-based alloys with similar particle sizes and volume fractions [47].

Equation (2) is valid for all particle sizes up to the critical diameter, $d_{\text {Oro }}$, where Orowan looping becomes favourable. The contribution from Orowan looping is given by

$$
\sigma_{\text {Oro }}=\frac{3 M \mu b}{2 L}
$$

and the critical size for a given volume fraction can be found from the $\sigma_{O r o}=\sigma_{p}$. In the presence of a fraction of particles larger than $d_{O r o}$ in a multimodal distribution, the Orowan contribution in is weighted by its number fraction, $w_{O}$, in Equation (7).

\subsubsection{Precipitate sizes and fractions}

In order to estimate the average particle sizes for the different heat treatments, ImageJ was used to extract the size distributions of $\gamma^{\prime}$ from a set of five SEM images for each condition taken at a magnification of 80,000 times. The levels of the greyscale images were optimized for contrast between particles and matrix, and the images were subsequently binarized based on a manually selected threshold levels, holes were automatically filled, and the particle analysis feature in ImageJ were then used to extract the size of each identified particle. The number of measured particle in each case was $1755(\mathrm{ST}+\mathrm{A}), 7900(\mathrm{MA}+\mathrm{A})$ and $5254(\mathrm{MA}+\mathrm{LTA})$. Histograms of the size distributions are shown in Figure 17. In the figures the thick solid line represents the critical size for Orowan looping $\left(d_{O r o}=201 \mathrm{~nm}\right)$, which is only exceeded in the MA+LTA case. For the two unimodal distributions (ST+A, Figure 17(a)) and (MA+A, Figure 17(b)) the thin 
vertical line corresponds to the average size $\left(d_{a v}\right)$. For the bimodal distribution (MA+LTA, Figure $17(\mathrm{c}))$ the distribution was split into a small distribution $(d<90 \mathrm{~nm})$, a large distribution $\left(90<d<d_{\text {Oro }}\right)$, and a distribution for $d>d_{\text {Oro }}$. Here the thin solid line represents the average of the small distribution $\left(d_{s}\right)$, the dashed line is the average of the large distribution $\left(d_{l}\right)$ and the dotted line is the average of the fraction above $d_{O r o}\left(d_{O}\right)$. It should be noted that the interaction volume in the SEM investigations gives information from not only the particles cut by the cross-section surface, but also from some nm below the surface. Since the distance between the smaller particles is short, a number of subsurface particles will also be (partly) imaged. Such subsurface particles can be readily seen in e.g. Figure 4(c), and will be counted in the analysis since the thresholding in Image $J$ is not sufficient to discriminate them from the surface-breaking particles. This will lead to an overestimation of the number fraction of small particles in the histograms, which is obvious especially from ST+A case, Figure 17(a), where this fraction also contributes to a too small estimate of the mean size. An approximate correction for this yields the mean value represented by the dashed line in Figure 17(a). The correction is negligible for the other two cases. For the MA+LTA case, the number fractions of small $\left(w_{s}\right)$ and large $\left(w_{l}\right)$ $\gamma^{\prime}$, as well as $w_{O}$ ) were calculated directly from the histogram in Figure 17(c).

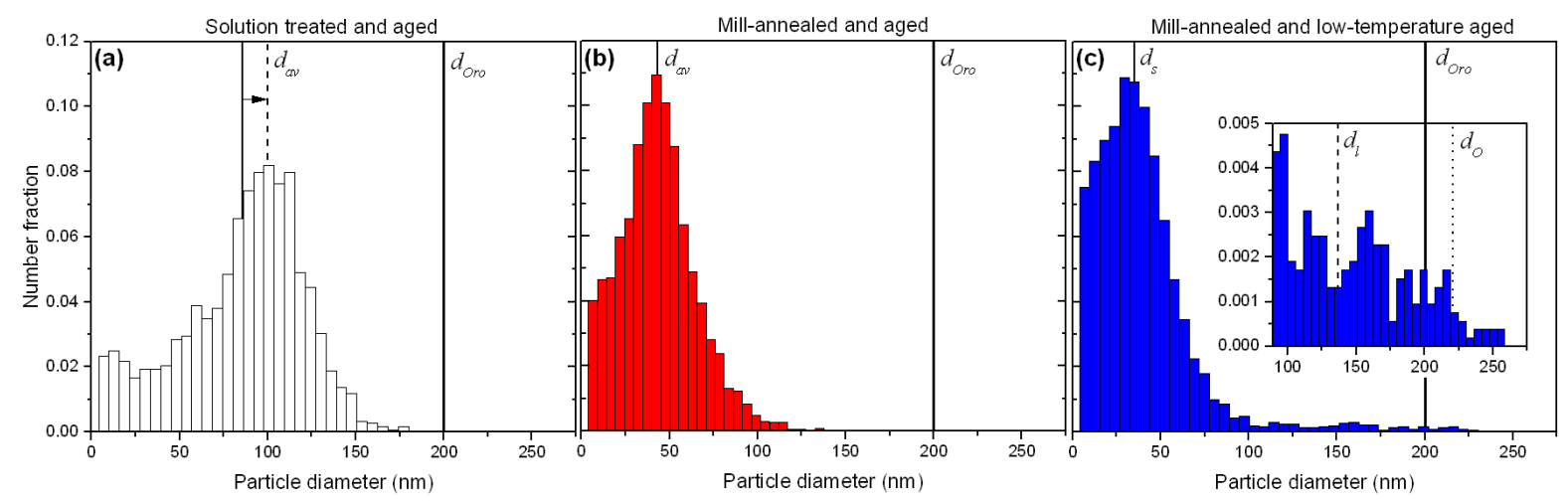

Figure 17. Histograms of the particle size distributions for the (a) ST+A, (b) MA+A, and (c) MA+LTA material. The thick line indicates the critical size for Orowan looping $\left(d_{\text {Oro }}\right)$. The thin solid lines in (a) and (b) shows the average particle size. The dashed line in (a) indicates the average size after approximate correction for the overrepresentation of small particles. In (c), the thin solid line is the average size of the small $\gamma^{\prime}(d<90 \mathrm{~nm})$, whereas the dashed and dotted lines are the average of the large population $\left(90 \mathrm{~nm}<d<d_{\text {Oro }}\right)$, and the population above $d_{\text {Oro }}$, respectively. 
In addition to the average radii I, it is necessary to estimate the volume fraction of $\gamma^{\prime}$. Due to the difficulties associated with the finite interaction volume mentioned above, it is difficult to do this from the SEM images. Instead it was assumed that the $\gamma$ ' fraction had reached thermodynamic equilibrium. Calculations using JMatPro show that the equilibrium fraction, equal to 0.18 , is reached within an hour at $788{ }^{\circ} \mathrm{C}$ (see Fig. $12(\mathrm{~b})$ ), making this assumption reasonable. One complicating factor is that $\gamma^{\prime}$ also precipitates in the grain boundaries in the case of the MA+LTA treatment. This fraction, $f_{g b}$, does not contribute to the particle strengthening and must be subtracted from the equilibrium fraction (note that in Eq. (7) and (8) the total volume fraction is used throughout, since it represents the average spacing [38], so it is not necessary to separate the individual volume fractions corresponding to $d_{s}, d_{l}$ and $d_{O}$ ). This is done by using ImageJ to calculate the total area of grain boundary $\gamma^{\prime}$ in a number of images similar to Fig. 10(b) (but at lower magnification), and dividing this area with the total length of the boundaries in the images, thus obtaining an equivalent thickness, $\delta$, corresponding to an imagined continuous grain boundary g' film. From this, the volume fraction of grain boundary $\gamma^{\prime}$ can be estimated for a given grain size, with radius $R$, according to [49]

$$
f_{g b}=1-\frac{R^{3}}{(R-\delta / 2)^{3}}
$$

In the present case this amounts to around 0.004 ( $\delta=150 \mathrm{~nm}, R=50 \mu \mathrm{m})$, giving a total fraction of intragranular $\gamma^{\prime}$ of 0.176 .

\subsubsection{Other strengthening contributions}

On order to calculate the total yield strength of the material, one also need to consider the contributions from base strength of pure $\mathrm{Ni}, \sigma_{0}$, the grain size strengthening, $\sigma_{D}$, as well as the solid solution strengthening $\sigma_{s s}$. The grain size contribution is given by

$$
\sigma_{D}=\frac{\kappa}{D^{1 / 2}}
$$

where $\mathrm{D}$ is the grain size (diameter) and $\kappa$ is the Hall-Petch slope. The base strength, $\sigma_{0}$, is the intrinsic (lattice friction) strength and, which is given by $M \cdot \tau_{C R S S}$, where $\tau_{C R S S}$ is the critical resolved shear stress. This has been estimated to be around 17.5 $\mathrm{MPa}$ for grown Ni single crystals [50], corresponding to a value of $\sigma_{0}$ of $53.5 \mathrm{MPa}$. This, however, corresponds to a very low dislocation density (estimated in [50] to be around $10^{12} \mathrm{~m}^{-2}$. In the present case the dislocation density can be assumed to be higher than that, and indications from commercial vendors (e.g. [51]) rather indicates values of around 100-200 MPa for polycrystalline hotfinished and annealed products. It should be noted that these values include the contribution 
from grain size strengthening, and thus we assume the lower value $\sigma_{0}=100 \mathrm{MPa}$ as the HallPetch component will be added separately. The Hall-Petch slope is a function of the precipitation condition for Ni-based superalloys [52], and here we assume a value of $370 \mathrm{MPa}$ $\mu \mathrm{m}^{1 / 2}$, and note that the Hall-Petch contribution is of minor importance in the present case.

The solid solution strengthening is given by [53-55]

$$
\sigma_{s s}=(1-f)\left[\sum_{i}\left(a_{i} c_{i}^{1 / 2}\right)^{2}\right]^{1 / 2}
$$

where $c_{i}$ is the concentration and $a_{i}$ is the strengthening constant atomic species $i$, and the factor $(1-f)$ corrects for the fact that it is only the matrix that contributes to the solid solution strengthening [40]. The values of $a_{i}$ are taken from [55] and are given in Table 4. The composition of the matrix is taken from JMatPro simulations, where the equilibrium concentration of the $\gamma$ phase in the presence of $\gamma^{\prime}, \mathrm{M}_{23} \mathrm{C}_{6}, \mathrm{M}_{6} \mathrm{C}$ and $\mathrm{MC}$ was calculated at $788^{\circ} \mathrm{C}$ (see Table 4).

\subsubsection{Yield strength}

The different contributions are added according to [56]

$$
\sigma_{\text {yield }}=\left(\sigma_{0}^{k}+\sigma_{D}^{k}+\sigma_{S S}^{k}+\sigma_{p}^{k}\right)^{1 / k}
$$

In [56] values of $k=1.19$ for under-aged and 1.13 for peak-aged Ni-base superalloys with $\gamma^{\prime}$ volume fractions ranging from 0.07 to 0.47 , were reported. Here the exact value of $k$ is not known, but we assume a value in the higher range (1.17) for $\mathrm{ST}+\mathrm{A}$ and $\mathrm{MA}+\mathrm{A}$, and a value in the lower range (1.14) for the MA+LTA case due to the presence of very large $\gamma^{\prime}$ (see Fig. $17(\mathrm{c}))$.

A summary of the values of the physical constants used is given in Table 5, and the resulting values of the yield strength for the different conditions are shown in Table 6 , together with the individual contributions from the different components and a summary of the microstructural variables used in the calculations. The calculated values agree exceptionally well with the measured strength levels, all falling within $2 \%$ of the experimental average values. Although this will be affected by making slightly different choices and assumptions regarding the input parameters (in particular $\sigma_{0}, \gamma_{A P B}$ and $k$ will have a large influence on the results), it is encouraging that the unified model can be used to estimate the effect of microstructure, both unimodal and bimodal $\gamma^{\prime}$ distributions, on the yield strength with sufficient precision to be 
useful for qualitatively designing heat treatments. Figure 18 shows the effect of the selected value of $k$ on the error between predicted and measured yield strengths for the different heat treatments. It should be noted that, based on the current data, there is a $k$-range within which the predicted yield strength for all microstructures fall within $\pm 3 \%$. This indicates that a single value of $\mathrm{k} \approx 1.15$ could be used to adequately predict the relationship between microstructure and yield strength of Haynes 282 for wide range of $\gamma^{\prime}$ sizes. The experimental results necessary for these calculations are limited to grain size and $\gamma^{\prime}$ measurements, which can be routinely obtained using optical microscopy and SEM, respectively, and otherwise only rely on thermodynamic prediction of the $\gamma^{\prime}$ volume fraction and matrix composition.

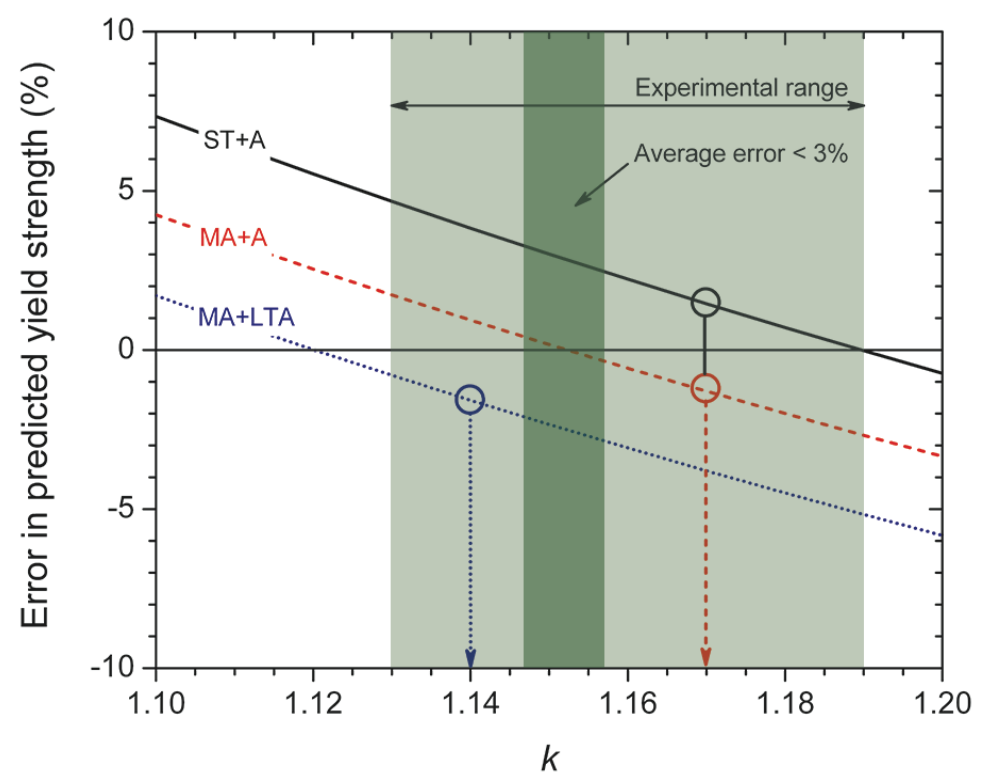

Figure 18. Error in predicted yield strength as a function of $k$ (all other parameters constant) for all the heat treated condition. The arrows mark the selected values of $k$, and the dark and light green areas mark the range of experimentally measured $\mathrm{k}$ values in Ni-base superalloys and the range corresponding to an average error of less than $3 \%$, respectively.

\section{CONCLUSIONS}

In the present work, the effect of heat treatment on the microstructure and room temperature tensile properties of Ni-base superalloy Haynes 282 was investigated.

Applying a standard two-step ageing $\left(1010{ }^{\circ} \mathrm{C} / 2 \mathrm{~h}+788^{\circ} \mathrm{C} / 8 \mathrm{~h}\right)$ to the as-received, millannealed, material resulted in a the presence of discrete grain boundary carbides and finely 
dispersed intragranular $\gamma^{\prime}$, with an average size of $43 \mathrm{~nm}$. This condition showed excellent room temperature strength and ductility.

The introduction of a solution treatment at $1120^{\circ} \mathrm{C}$ resulted in grain growth. During subsequent standard two-step ageing, no carbides precipitated during the $1010{ }^{\circ} \mathrm{C}$ stabilization step (contrary to observations during ageing of the mill-annealed material without solutionizing). As a result, carbide precipitation instead occurred during the $788{ }^{\circ} \mathrm{C}$ ageing, which produced an interconnected network in grain boundaries. The $\gamma^{\prime}$ formed was coarser, with an average size of $100 \mathrm{~nm}$. The coarser $\gamma^{\prime}$ led to a significant reduction in the strength level, and the interconnected carbides resulted in quasi-brittle fracture with a $50 \%$ reduction in ductility. The likely reason for the change in $\gamma^{\prime}$ precipitation is the reduction in nucleation sites due to recovery during the solution treatment. Furthermore, during grain growth the grain boundaries moved away from their initial position, supposedly leaving segregating species behind. Thus, in their new positions the chemistry would be different, which is a potential explanation for the observed changes in the carbide precipitation behavior.

Finally, reducing the temperature of the stabilization step to $996{ }^{\circ} \mathrm{C}$ during ageing of the MA material produced a bi-modal $\gamma^{\prime}$ distribution, and grain boundaries decorated by discrete carbides accompanied by $\gamma^{\prime}$. This condition showed very similar strength and ductility levels as the standard ageing of mill-annealed material. This is promising since both grain boundary $\gamma^{\prime}$ and a bi-modal intragranular $\gamma^{\prime}$ distribution can be used to tailor the mechanical properties to specific applications.

On a final note, it was shown that a yield strength model based on the unified approach for precipitation strengthening developed by Galindo-Nava et al. [40] gave excellent agreement with the observed yield strengths for all three conditions discussed above.

Table 4. Solid solution strengthening coefficients for the different elements $\left(a_{i}\right)$, and equilibrium concentration of solute elements in the matrix $\left(c_{i}\right)$ from JMatPro calculations.

\begin{tabular}{|c|c|c|c|c|c|c|}
\hline Element & Al & Co & Cr & Fe & Mo & Ti \\
\hline$a_{i}$ (MPa/at.\%) & 225 & 39.4 & 337 & 153 & 1015 & 775 \\
\hline$c_{i}$ (at.\%) & 1.60 & 11.3 & 25.8 & 0.90 & 5.70 & 0.50 \\
\hline
\end{tabular}


Table 5. Values of the physical constants used in the calculations.

\begin{tabular}{|c|c|c|}
\hline Parameter & Value & Unit \\
\hline$M$ & 3.06 & - \\
\hline$b$ & 0.248 & $\mathrm{~nm}$ \\
\hline$\mu$ & 82 & $\mathrm{GPa}$ \\
\hline$\gamma_{A P B}$ & 0.18 & $\mathrm{~J} / \mathrm{m}^{2}$ \\
\hline$\kappa$ & 370 & $\mathrm{MPa} \mu \mathrm{m}^{1 / 2}$ \\
\hline
\end{tabular}

Table 6. Input and results from the yield strength calculations.

\begin{tabular}{|c|c|c|c|c|}
\hline & ST+A & MA+A & MA+LTA & Unit \\
\hline$D$ & 200 & 100 & 100 & $\mu \mathrm{m}$ \\
\hline$f$ & 0.18 & 0.18 & 0.176 & - \\
\hline$d_{a v}$ & 100 & 43.4 & - & $\mathrm{nm}$ \\
\hline$d_{s}$ & - & - & 35 & $\mathrm{~nm}$ \\
\hline$d_{l}$ & - & - & 137 & $\mathrm{~nm}$ \\
\hline$d_{O}$ & - & - & 221 & $\mathrm{~nm}$ \\
\hline$w_{s}$ & - & - & 0.950 & - \\
\hline$w_{l}$ & - & - & 0.043 & - \\
\hline$w_{O}$ & - & - & 0.007 & - \\
\hline$k$ & 1.17 & 1.17 & 1.14 & $\mathrm{MPa}$ \\
\hline$\sigma_{0}$ & 100 & 100 & 100 & $\mathrm{MPa}$ \\
\hline$\sigma_{D}$ & 26 & 37 & 37 & $\mathrm{MPa}$ \\
\hline$\sigma_{s s}$ & 249 & 249 & 249 & $\mathrm{MPa}$ \\
\hline$\sigma_{p}$ & 394 & 485 & 469 & $\mathbf{M P a}$ \\
\hline$\sigma_{\text {yield }}$ & $\mathbf{6 5 9}$ & $\mathbf{7 5 0}$ & $\mathbf{7 5 3}$ & \\
\hline
\end{tabular}

\section{ACKNOWLEDGEMENTS}

The funding for the present work has been provided by the Swedish Agency for Innovation (VINNOVA), through the Swedish National Aeronautical Research Program (NFFP) grants no 2010-01221 and 2013-01154, which is gratefully acknowledged. GKN Aerospace Engine Systems AB is kindly acknowledged for supplying the material. 


\section{REFERENCES}

[1] R.C. Reed: The Superalloys (Fundamentals and Applications), Cambridge University Press UK, 2006.

[2]. C.H. Lund, H.J Wagner, Identification of microconstituents in superalloys, Defense metals information center, Battle memorial institute, November 1962 (DMIC memorandum 160), 122

[3] H.J. Beattie Jr., F.L Ver Snyder, Microconstituents in High temperature alloys, Trans. of ASM, 45 (1953) 397-428

[4] J. Chander, The hardening mechanism and corrosion resistance of nickel-base alloys: A review, Canad. Metall. Quart., 3 (1964) 57-77

[5] H.E. Collins, Relative stability of carbide and intermetallic phases in nickel base superalloys, TMS superalloy conference, (1968) 171-198.

[6] C.P. Sullivan, M.P. Donachie, Some effects of microstructure on the mechanical properties of nickel base superalloys, National metal congress, (1966) 1-29.

[7] F.-S. Yu, X.-F. Sun, C. Yuan, H.-R. Guan, Z.-Q. Hu, Effect of heat treatment on microstructure and high temperature tensile properties of cast nickel-base superalloy with high W, Mo and Nb contents, Trans. Nonferrous Met. Soc. of China, 12 (2002) 06-11.

[8]. E.G. Richards, R.M. Cook, Factors influencing the stability of nickel-base hightemperature alloys, TMS superalloy conference, 1968, 1-25.

[9] W. Betteridge, A.W. Franklin, The effect of heat-treatment and structure on the creep and stress-rupture properties of Nimonic 80A, Journal of the Institute of Metals, 85 (1956) 473-479.

[10] J.R. Mihalisin, J.S. Iwanski, Microstructural study of the response of a complex superalloy to heat treatment, Trans. Met.of AIME, 215 (1959) 912-916. 
[11] S.A. Sajjadi, S. Nategh, R.I.L. Guthrie, Study of microstructure and mechanical properties of high performance Ni-base superalloy GTD-111, Mater. Sci. Eng. A, 325 (2002) 484-489.

[12] R.M. Kearsey, J. Tsang, S. Oppenheimer, E. McDevitt, Microstructural effects on the mechanical properties of ATI718Plus Alloy, Journal of Metals, 64 (2012) 241-251.

[13] E. Balikci, A. Raman, R.A. Mirshams, Influence of various heat treatments on the microstructure of Polycrystalline IN738LC, Metall. Mater.Trans A, 28A (1997)1993-2002.

[14] L. Pike, Development of a fabricable gamma-prime strengthened superalloy, Proceedings of the International Symposium on Superalloys (2008) 191-200.

[15] http://www.haynesintl.com/pdf/h3173.pdf

[16] M.P. Jackson, R.C. Reed, Heat treatment of UDIMET 720Li: the effect of microstructure on properties. Mater. Sci. Eng. A, A259 (1999), 85-97.

[17] https://imagej.nih.gov/ij/

[18] http://www.sentesoftware.co.uk/jmatpro.aspx

[19] H.U. Hong, I.S. Kim, B.G. Choi, M.Y. Kim, C.Y. Jo, The effect of grain boundary serration on creep resistance in a wrought nickel-based superalloy. Mater. Sci. Eng., A517 (2009) 125131.

[20] Y.S. Lim, D.J. Kim, S.K. Hwang, H.P. Kim, S.W. Kim, $\mathrm{M}_{23} \mathrm{C}_{6}$ precipitation behaviour and grain boundary serration in Ni-based Alloy 690, Mater. Char, 96 (2014) 28-39.

[21] B. Tang, L. Jiang, R. Hu, Q. Li, Correlation between grain boundary misorientation and $\mathrm{M}_{23} \mathrm{C}_{6}$ precipitation behavior in a wrought Ni-based superalloy, Mater. Char. 78 (2013) 144150.

[22] G.P. Sabol, R. Stickler, Microstructure of Nickel-based superalloys, Phys. Stat.sol 1969,35 pp 11-52. 
[23] T.J. Garhossen, G.P. McCarthy, Low temperature carbide precipitation in a Nickel base superalloy. Metall. Trans. 16A (1985) 1213-1223.

[24] H. White, M. Santella, E.D. Specht, Weldability of Haynes 282 Alloy for new fabrications and after service exposure, Energy Materials, 2009,Vol 4, pp 84-91.

[25] M. Fährmann, P. Pratzl, O. Paris, E. Fährmann, W.C. Johnson, Influence of coherency stress on microstructural evolution in model Ni-Al-Mo alloys. Acta Metall. Mater. 43 (1995) 1007-1022.

[26] W.M. Mullins, R.F. Sekerka, Morphological stability of a particle growing by diffusion or heat flow. J. Appl. Phys. 34 (1963) 323-329.

[27] R.D. Doherty, Role of interfaces in kinetics of internal shape change. Met. Sci. 16 (1982) $1-13$.

[28] R.A. Ricks, A.J. Porter, R.C. Ecob, The growth of $\gamma^{\prime}$ precipitates in Nickel-base superalloys. Acta Metall. 31 (1983) 43-53.

[29] S. Olovsjö, A. Wretland, G. Sjöberg, The effect of grain size and hardness of wrought Alloy 718 on the wear of cemented carbide tools. Wear 268 (2010) 1045-1052.

[30] S. Olovsjö, A. Wretland, G. Sjöberg, The effect of grain size and hardness of Waspaloy on the wear of cemented carbide tools. Int. J. Adv. Manuf. Technol. 50 (2010) 907-915.

[31] J.A. Del Valle, A.C. Picasso, R. Romero, Work-hardening in Inconel X-750: Study of stage II. Acta Mater. 46 (1998) 1981-1988.

[32] K.V.U. Praveen, G.V.S. Sastry, V. Singh, Work-hardening behavior of the Ni-Fe based superalloy IN718. Metall. Mater. Trans. 39A (2008) 65-78.

[33] J. Mittra, J.S. Dubey, U.D. Kulkarni, G.K. Dey, Role of dislocation density in raising the stage II work-hardening rate of Alloy 625. Mater. Sci. Eng. A 5012 (2009) 87-91. 
[34] L.M. Cheng, W.J. Poole, J.D. Embury, D.J. Lloyd, The influence of precipitation on the work-hardening behavior of the Aluminum alloys AA6111 and AA7030. Metall. Mater.Trans. 34A (2003) 2473-2481.

[35] D. Locq, P. Caron, S. Raujol, F. Pettinari-Sturmel, A. Coujou, N. Clément, On the role of tertiary $\gamma^{\prime}$ precipitates in creep behaviour at $700^{\circ} \mathrm{C}$ of a PM Disk Superalloy, Superalloys 2004, pp 179-187.

[36] J. Telesman, T.P. Gabb, A. Garg, P. Bonacuse, J. Gayda, Effect of microstructure on time dependent fatigue crack growth behavior in a P/M turbine disk alloy, Superalloys 2008, pp. 807-906.

[37] J.W. Martin, Precipitation hardening - Theory and applications, 2nd edition. ButterworthHeinemann, Oxford, UK, 1998

[38] M.R. Ahmadi, E. Povoden-Karadeniz, L. Whitmore, M. Stockinger, A. Falahati, E. Kozeschnik, Yield strength prediction in Ni-base alloy 718Plus based on thermo-kinetic precipitation simulation. Mater. Sci. Eng. A 608 (2014) 114-122.

[39] R.W. Kozar, A. Suzuki, W.W. Milligan, J.J. Schirra, M.F. Savage, T.M. Pollock, Strengthening mechanisms in polycrystalline multimodal nickel-base superalloys. Metall. Mater. Trans. 40A (2009) 1588-1603.

[40] E.I. Galindo-Nava, L.D. Connor, C.M.F. Rae, On the prediction of the yield stress of unimodal and multimodal $\gamma^{\prime}$ nickel-base superalloys. Acta Mater. 98 (2015) 377-390.

[41] P. Veyssiere, J. Douin, P. Beauchamp, On the presence of super lattice intrinsic stacking faults in plastically deformed $\mathrm{Ni}_{3}$ Al. Phil. Mag. A 51 (1985) 469-483.

[42] K.J. Hemker, M.J. Mills, Measurements of antiphase boundary and complex stacking fault energies in binary and B-doped $\mathrm{Ni}_{3} \mathrm{Al}$ using TEM. Phil. Mag. A 68 (1993) 305-324. 
[43] H.P. Karnthaleret, E.T. Mühlbacher, C. Rentenberger, The influence of the fault energies on the anomalous mechanical behaviour of $\mathrm{Ni}_{3} \mathrm{Al}$ alloys. Acta Mater. 44 (1996) 547-560.

[44] T. Kruml, B. Viguier, J. Bonneville, J.L. Martin, Temperature dependence of dislocation microstructure in $\mathrm{Ni}_{3}(\mathrm{Al}, \mathrm{Hf})$. Mater. Sci. Eng. A 234-236 (1997) 755-575.

[45] D.M. Dimiduk, A.W. Thompson, J.C. Williams, The compositional dependence of antiphase-boundary energies on the mechanisms of anomalous flow in $\mathrm{Ni}_{3} \mathrm{Al}$ alloys. Phil. Mag. A 67 (1993) 675-698.

[46] M. Vittori, A. Mignone, On the antiphase boundary energy of $\mathrm{Ni}_{3}(\mathrm{Al}, \mathrm{Ti})$ particles. Mater. Sci. Eng. 74 (1985) 29-37.

[47] E. Nembach, S. Schänzer, K. Trinckauf, The antiphase boundary energy of $\gamma^{\prime}$ precipitates in nickel-based superalloys. Phil. Mag. A 66 (1992) 729-738.

[48] D. Baither, C. Rentenberger, H.P. Karnthaler, E. Nembach, Three alternative experimental methods to determine the antiphase-boundary energies of the $\gamma^{\prime}$ precipitates in superalloys. Phil. Mag. A 82 (2002) 1795-1805.

[49] J.E. Darnbrough, B. Roebuck, P.E.J. Flewitt, The influence of temperature and grain boundary volume on the resistivity of nanocrystalline nickel. J. Appl. Phys. 118 (2015) 184302.

[50] D.M. Dimiduk, M.D. Uchic, T.A. Parthasarathy, Size-affected single-slip behavior of pure nickel microcrystals. Acta Mater. 53 (2005) 4065-4077.

[51] Special Metals Datasheet for Nickel 200 \& 201 (www.specialmetals.com)

[52] W. Mangen, E. Nembach, The effect of grain size on the yield strength of the $\gamma^{\prime}$-hardened superalloy Nimonic PE16. Acta Metall. 37 (1989) 1451-1463

[53] L.A. Gypen, A. Deruyttere, Multi-component solid solution hardening. Part 1 - Proposed model. J. Mater. Sci. 12 (1977) 1028-1033. 
[54] L.A. Gypen, A. Deruyttere, Multi-component solid solution hardening. Part 2 - Agreement with experimental results. J. Mater. Sci. 12 (1977) 1034-1038.

[55] Y. Mishima, S. Ochiai, N. Hamao, M. Yodogawa, T. Suzuji, Solid solution hardening of nickel - Role of transition metal and B-subgroup solutes. J. Trans. Jpn. Inst. Met. 27 (1986) 656-664.

[56] S. Schänzer, E. Nembach, The critical resolved shear stress of $\gamma^{\prime}$-strengthened nickel-based superalloys with $\gamma^{\prime}$-volume fractions between 0.07 and 0.47. Acta Metall. Mater. 40 (1992) 802-813. 